\title{
AN OVERVIEW OF STUDIES ON EARLY LIFE HISTORY OF FISH IN VIETNAM
}

\author{
Tran Duc Hau ${ }^{1, *}$, Tran Trung Thanh ${ }^{2}$, Ta Thi Thuy ${ }^{3}$, Kinoshita Izumi ${ }^{4}$ \\ ${ }^{1}$ Hanoi National University of Education, Ha Noi, Vietnam \\ ${ }^{2}$ VNU University of Science, Vietnam \\ ${ }^{3}$ Hanoi Metropolitan University, Ha Noi, Vietnam \\ ${ }^{4}$ Kochi University, Japan
}

Received 12 April 2019, accepted 28 May 2019

\begin{abstract}
Early stages from fertilized eggs to juveniles are important in the existence and development cycles of fish. At these stages, fish are still not fully developed, and are thus easily affected by environmental factors. Vietnam has a rich fish diversity, with ca 3000 species, and fishery resources play significantly roles not only in the daily lives of local residents but also in national economic development. Ichthyological studies in Vietnam have focused mainly on matured fish while early life history has so far been less researched. This paper presents an overview of studies in Vietnam related to early stages of fish and provides an orientation for this field in future.
\end{abstract}

Keywords: Larvae and juveniles, estuary, fishery resource, Vietnam.

Citation: Tran Duc Hau, Tran Trung Thanh, Ta Thi Thuy, Kinoshita Izumi, 2019. An overview of studies on early life history of fish in Vietnam. Tap chi Sinh hoc, 41(2): 1-12. https://doi.org/10.15625/0866-7160/v41n2.13752.

*Corresponding author email: hautd@hnue.edu.vn

C2019 Vietnam Academy of Science and Technology (VAST) 


\title{
TỔNG QUAN NGHIÊN CƯUU GIAI ĐOẠN SỚM CỦA CÁ Ở VIẸTT NAM
}

\author{
Trần Đức Hậu ${ }^{1, *}$, Trần Trung Thành ${ }^{2}$, Tạ Thị Thủy ${ }^{3}$, Kinoshita Izumi ${ }^{4}$ \\ ${ }^{1}$ Trường Đại học Sư phạm Hà Nội, Hà Nội, Việt Nam \\ ${ }^{2}$ Trường Đại học Khoa học Tự nhiên, Đại học Quốc gia Hà Nội, Việt Nam \\ ${ }^{3}$ Trường Đại học Thủ đô Hà Nội, Hà Nội, Việt Nam \\ ${ }^{4}$ Trường Đại học Kochi, Nhật Bản
}

Ngày nhận bài 12-4-2019, ngày chấp nhận 28-5-2019

\section{TÓM TẮT}

Trong chu kỳ sống của cá, giai đoạn từ trứng đến cá con có vai trò quan trọng, quyết định đến sự tồn tại và phát triển cá thể. Ở giai đoạn này, cơ thể của chúng chưa phát triển toàn diện vì vậy, dễ bị tác động bởi các yếu tố môi trường. Việt Nam có độ đa dạng cá khá cao, với gần 3000 loài và nguồn lợi cá đóng vai trò quan trọng trong đời sống của người dân cũng như sự phát triển kinh tế. Nghiên cứu về cá ở Việt Nam đã được tiển hành từ khá lâu, tuy nhiên, mới chỉ tập trung vào giai đoạn cá trưởng thành còn giai đoạn sớm rất ít nhận được sự quan tâm của các nhà khoa học. Bài viết này tổng hợp kết quả bước đầu về nghiên cứu giai đoạn sớm của cá góp phần làm rõ tầm quan trọng của nghiên cứu về lĩnh vực này ở Việt Nam.

Từ khóa: Âu trùng và cá con, cửa sông, nguồn lợi cá, Việt Nam.

*Địa chỉ liên hệ email: hautd@hnue.edu.vn

\section{MỞ ĐẦU}

Giai đoạn sớm trong sự phát triển của cá bao gồm trứng sau thụ tinh, âu trùng và cá con (Moser et al., 1984). Quá trình từ khi nở đến giai đoạn trưởng thành, cá có nhiều thay đổi về môi trường sống. Thí dụ: cá hồi (Oncorhynchus spp.) trưởng thành sống ở biển và di cư ngược lên suối để đẻ, cá chình (Anguilla spp.) sống ở sông hồ nước ngọt trong nội địa di cư ra biển để đẻ và con non quay về nơi mà con trưởng thành sinh sống (McDonald, 1988) hay ở các loài cá bơn (Pleuronectiformes), trứng trôi nổi trên biển, nở thành ấu trùng và sống ở các tầng nước trên, cùng với quá trình sinh trưởng và phát triển của cơ thể, cá sẽ dần chuyển xuống định cư ở đáy (Leis \& Carson-Ewart, 2000; Yagi et al., 2009).

Hình thái của cá cũng khác nhau giữa các giai đoạn. Sự thay đổi này dễ nhận thấy giữa con non và con trưởng thành và ngay ở các thời kỳ gần nhau ở giai đoạn sớm. Thí dụ: cá bơn, khi nở mắt ở hai bên cơ thể, nhưng khi lớn lên, mắt dịch chuyển về một bên (Leis \& Carson-Ewart, 2000; Yagi et al., 2009); cá chình, ấu trùng dạng lá liê̂u so với thân dạng lươn của con trưởng thành. Như vậy, để hiểu rõ về một loài cá, những nghiên cứu chi tiết về hình thái và sinh thái ở từng giai đoạn thực sự cần thiết.

Ngoài ý nghĩa lý thuyết và thực tiễn của nghiên cứu giai đoạn sớm ở cá như đã nêu, một số lý do cần thúc đẩy hướng nghiên cứu này, bao gồm nghiên cứu về giai đoạn sớm cũng là một phần trong nghiên cứu chung về từng giai đoạn, cũng như cả vòng đời của cá. Hơn thế, giai đoạn sớm của cá thường có nhiều sự biến đổi hơn giai đoạn trưởng thành. Tuy nhiên, các nghiên cứu từ trước tới nay đa phẩn tập trung vào cá trưởng thành. Bởi vậy nghiên cứu vể giai đoạn sớm cần được quan tâm hơn. Nghiên cứu về giai đoạn sớm đưa ra các đánh giá và dự đoán chính xác về mùa 
sinh sản, hay thời gian mà một loài nào đó đạt năng suất sinh sản cao nhất và mối tương quan với các yếu tố của môi trường. Các kết quả này sẽ giúp con người hiểu được ảnh hưởng các yếu tô môi trường đến sự phát triển và tồn tại của loài. Nghiên cứu về giai đoạn sớm cung cấp thông tin chung về nguồn lợi cá. Các nghiên cứu về nguồn lợi cá ở giai đoạn trưởng thành thường tốn kém về thực địa, chi phí mua, phân tích và bảo quản mẫu. Những kết quả trên đối tượng giai đoạn sớm có thể phản ánh đánh giá tương tự nhưng với chi phí thấp hơn. Như vậy nghiên cứu về giai đoạn sớm ở cá trước tiên cung cấp các kiến thức cơ bản phục vụ cho các nghiên cứu khác và là cơ sở để đưa ra các biện pháp bảo tồn, khôi phục và phát triển bền vững phù hợp đối với đối tượng cụ thể và cả hệ sinh thái.

Trên thế giới, hướng nghiên cứu này phát triển mạnh mẽ từ sau những năm 1980 (Leis, 2015) ở các nước như Hoa Kỳ, Australia, Nhật Bản, Nam Phi với những kết quả chính được tổng hợp trong một số công trình tiêu biểu như: Uchida et al. (1958), Mito (1966), Delsman (1972), Leis et al. (1983, 1989, 2000, 2004), Moser et al. (1984), Okiyama (1988, 2014), Moser (1996), Jeyaseelan (1998), Neira et al. (1998), Richards (2006), Fahay (2007) và Kendall (2011). Tuy nhiên, ở nhiều khu vực các nghiên cứu về giai đoạn sớm của cá còn ít hoặc chưa được tiến hành, trong đó có Việt Nam. Ở Việt Nam, những nghiên cứu về nguồn giống đã được tiến hành từ khá sớm (ví dụ Nguyễn Hữu Phụng, 1991; Đỗ Văn Nguyên, 1977, 1981, 1999, 2004; Đỗ Văn Nguyên và nnk., 2006; Đỗ Văn Nguyên \& Phạm Quốc Huy, 2007; Phạm Quốc Huy và nnk., 2014a, b, 2015, 2016, 2017). Tuy nhiên, các kết quả này chưa đánh giá được toàn bộ các hệ sinh thái khác nhau ở Việt Nam. Gần đây, nhiều công trình tập trung nghiên cứu ấu trùng, cá con ở các hệ sinh thái cửa sông hay rừng ngập mặn. Các kết quả bước đầu này tạo đà thúc đẩy mạnh mẽ cho hướng nghiên cứu đầy tiềm năng và ý nghĩa này ở Việt Nam. Bài viết này tổng quan nghiên cứu giai đoạn sớm cá ở Việt Nam nhằm đánh giá những kết quả bước đầu về đa dạng thành phần loài (vùng nước xa bờ, vùng cửa sông và rừng ngập mặn), đặc điểm phân bố và hình thái ấu trùng, cá con và đồng thời bàn luận về tiềm lực cũng như định hướng nghiên cứu về lĩnh vực này trong thời gian tới.

\section{KẾT QUẢ VÀ THẢO LUẬN \\ Thành phần loài, phân bố giai đoạn sớm cá ở vùng nước xa bờ}

Nghiên cứu về trứng cá, ấu trùng và cá con ở Việt Nam được tiến hành những năm 1930, đặc biệt từ năm 1959 với sự tài trợ các chương trình hợp tác, hướng nghiên cứu này mới thực sự được chú ý (theo Nguyễn Hữu Phụng, 1991). Sau năm 1970, hướng nghiên cứu này ở vùng biển Việt Nam được quan tâm nhiều hơn với các công bố của Nguyễn Hữu Phụng và nnk. (1971, 1973, 1991, 2002) hay các báo cáo đề tài của Đỗ Văn Nguyên và nnk. (1977, 1981, 1999, 2004, 2006, 2007), Phạm Quốc Huy và nnk. (2014b).

Năm 1991, Nguyễn Hữu Phụng tổng hợp kết quả từ các đề tài, dự án hợp tác với các nhà khoa học trong và ngoài nước từ năm 1959 đến 1983. Công trình này cho thấy trứng cá, ấu trùng và cá con ở vùng biển Việt Nam phong phú, xuất hiện quanh năm, nhiều loài có thời gian xuất hiện rât dài. Mật độ trứng cá, ấu trùng và cá con được tổng hợp và so sánh giữa các tháng và các vùng khác nhau. Mật độ đạt cao nhất vào tháng 5 và ở vùng biển vịnh Bắc Bộ và phía Tây Nam Bộ. Tác giả đã chỉ ra rằng sự phân bố của trứng cá, âu trùng và cá con đã phản ánh vùng tập trung của bãi đẻ, nhất là các loài cá nổi ven bờ. Ở vịnh Bắc Bộ, thời kỳ gió mùa tây nam là mùa vụ tập trung của trứng cá. Đây là những tổng kết có giá trị và có ý nghĩa định hướng cho các điều tra sau này cả cho cá xa bờ và gần bờ. Mặc dầu vậy, những nghiên cứu giai đoạn này chủ yếu tập trung vào định loại đến bậc họ và phân tích, đánh giá biến động mật độ, số lượng mà ít các mô tả chi tiết các giai đoạn phát triển cá thể. Do đó chưa đưa ra những nhận định chính xác về mùa vụ sinh sản, sự phân bố của từng loài.

Giai đoạn sớm của cá ở các vịnh, rạn san hô, đất ngập nước ven biển hay đầm cũng được quan tâm (Nguyen et al., 2002), nổi bật là tác giả Võ Văn Quang. Tác giả và các cộng sự công bố thành phần loài, phân bố trứng cá, 
âu trùng và cá con ở các khu vực nghiên cứu (Võ Văn Quang và nnk., 2004a, b, 2010, 2012, 2015; Võ Văn Quang, 2013a). Đây là các nghiên cứu thể hiện tính kế thừa rõ nét từ những công trình thực hiện ở vùng xa bờ của vịnh Bắc Bộ. Từ năm 2002 đến 2015, các nghiên cứu tập trung vào vùng biển gần bò̀ tỉnh Khánh Hòa, vùng ven biển bắc Bình Thuận, trong vùng san hô (Cù Lao Chàm Côn Đảo), đầm Thị Nại (tỉnh Bình Định), đất ngập nước ven biển tỉnh Quảng Nam hay rạn san hô vịnh Nha Trang và vùng lân cận. Có thể thấy nhóm tác giả tập trung chủ yếu vào khu vực Nam Trung Bộ. Mặc dù thời gian thực hiện trong nhiều năm, tần suất thu mẫu không theo chu kỳ nên rất ít nghiên cứu chỉ ra được mùa vụ xuất hiện giai đoạn sớm của cá ở khu vực nghiên cứu. Trong các họ cá, Gobiidae vẫn là họ chiếm ưu thế về số lượng loài và số lượng mẫu thu được; tiếp theo là họ Clupeidae. Như vậy, các họ chiếm ưu thế ở vịnh Bắc Bộ vẫn thể hiện rõ trong các điều tra này. So với các điều tra ở vùng nước xa bờ, nhiều loài được định danh hơn.

Gần như trùng với thời gian cho các nghiên cứu ở vùng ven biển Nam Trung Bộ như đã trình bày, từ 2003 đến 2016, một số tác giả đã khái quát bức tranh toàn cảnh về thành phần loài, phân bố của trứng cá, ấu trùng và cá con ở vùng biển vịnh $\mathrm{Bắc} B$ Bộ, từ đó đưa ra những vùng có mật độ cao hay mùa vụ sinh sản của cá (Phạm Quốc Huy và nnk., 2014a, b, 2015, 2016, 2017). Có thể nói đây là tập hợp các công trình toàn vẹn nhất về giai đoạn sớm của cá ở vịnh Bắc Bộ, với danh sách hơn 215 loài của 92 họ cá thu được. Các họ ưu thế về số lượng loài gồm Carangidae, Scombridae, Engraulidae, Clupeidae, Leiognathidae và Synodontidae. Như vậy, kết quả này có phần khác biệt so với Nguyễn Hữu Phụng (1991) khi kết luận họ Clupeidae chiếm ưu thế nhất ở vùng biển Việt Nam. Các tác giả cũng nhận xét trứng cá, ấu trùng và cá con chủ yếu phân bố ở tầng mặt và càng xa bờ hay càng sâu, số lượng các đơn vị phân loại càng tăng. Điều đó cho thấy tiềm năng cao để phát hiện, nâng tổng số loài cá ở giai đoạn sớm khi đầu tư cơ sở vật chất và năng lực cán bộ. Trứng cá, ấu trùng và cá con ở vịnh Bắc
Bộ cũng có sự biến đổi theo mùa rõ rệt, tập trung vào mùa Xuân. Mặc dù các tác giả đã đưa ra danh sách các loài cá thu được, tuy nhiên vẫn còn nhiều loài chưa được định danh hay mô tả để có thể là tiền đề cho các nghiên cứu sau này.

Trên đây là những kết quả có ý nghĩa vì thực hiện trên một phạm vi rộng lớn về thời gian và không gian, đồng thời đã có những nhận xét về đặc điểm phân bố trứng cá, âu trùng và cá con ở vùng biển xa bờ hay gần bờ. Tuy vậy, các nghiên cứu chi tiết về mô tả hình thái giai đoạn sớm của cá ít được thực hiện, chỉ với một số công trình như Nguyễn Hữu Phụng $(1976,1978,1980)$ và Võ Văn Quang (2013b).

\section{Thành phần loài ấu trùng và cá con ở cửa sông và rừng ngập mặn}

Như đã trình bày ở trên, dẫn liệu ấu trùng và cá con ở hệ sinh thái cửa sông và rừng ngập mặn ít được biết đến ở Việt Nam (Nguyễn Hữu Phụng và nnk., 1982). Mặc dù, các hệ sinh thái này đang có những biến đổi theo hướng tiêu cực do các hoạt động của con người cũng như biến đổi khí hậu toàn cầu. Sau đây là một số kết quả bước đầu ở khu vực cửa sông Bắc Việt Nam.

Ở cửa sông $\mathrm{Ka}$ Long (nằm trên biên giới Việt Nam và Trung Quốc), Ta et al. (2011) đã báo cáo danh sách hơn 48 loài cá ở giai đoạn ấu trùng, cá con ở cửa sông Ka Long và cửa sông Tiên Yên (tỉnh Quảng Ninh) sau thực địa mỗi tháng một lần từ tháng 10/2010 đến tháng 2/2011. Sau đó, ở cửa sông Ka Long (tỉnh Quảng Ninh), được sự tài trợ của Quỹ IFS, Tran (2017) đã tiến hành thực địa, thu mẫu mỗi tháng một lần tại vùng nước giữa dòng và ven bờ từ tháng $9 / 2014$ đến tháng $8 / 2015$. Kết quả thu được khoảng 100 loài của 33 họ trong 12 bộ cá ở giai đoạn sớm.

Ở cửa sông Tiên Yên (tỉnh Quảng Ninh), được tài trợ bởi Quỹ Nagao, Ta (2014) đã tiến hành thu mẫu ven bờ cửa sông Tiên Yên từ tháng $3 / 2013$ đến tháng $2 / 2014$. Kết quả thu được 50 loài của 25 họ cá ở giai đoạn sớm.

Ở cửa sông Sò, tỉnh Nam Định (một phân lưu của sông Hồng). Trần Trung Thành và 
nnk. (2017) tiến hành thực địa với phương pháp tương tự như trên ở vùng sóng vỗ cạnh cửa sông Sò từ tháng 11/2013 đến tháng 10/2014 đã thu được 45 loài cá thuộc 23 họ và 9 bộ ở giai đoạn sớm. Nghiên cứu này tiến hành thu mẫu theo 3 thời điểm trong ngày (sáng, trưa, chiều). Sự phân bố ấu trùng, cá con biến đổi theo mùa (mùa mưa nhiều loài hơn mùa khô), theo thời gian trong ngày (buổi trưa nhiều nhất) và theo độ đục.

Tran et al. (2017b) dựa vào 3 công trình (Ta, 2014; Tran, 2017; Trần Trung Thành và nnk., 2017) đã khái quát về ấu trùng, cá con ở các cửa sông, Bắc Việt Nam và các tác giả cho thấy các loài cá nhiệt đới chiếm ưu thế trong thành phần loài, tuy nhiên vẫn có xuất hiện các loài cá ôn đới ở các khu vực này, do vậy, Bắc Việt Nam được coi như là vùng chuyển tiếp. Với tần suất thu mẫu mỗi tháng một lần ở dọc theo cửa sông, các nghiên cứu trền có thể đánh giá sự biến động thành phần loài, sự phân bố ấu trùng, cá con theo thời gian và theo không gian, từ đó có thể xác định đặc điểm di cư, mùa sinh sản của các loài cá mà giai đoạn sớm xuất hiện ở môi trường cửa sông. Dẫn liệu phân bố ấu trùng, cá con chỉ ra rằng nhiều loài sử dụng các cửa sông như vùng ương dưỡng quan trọng. Đây là những đề tài có tính tiên phong ở hệ sinh thái cửa sông của Việt Nam.

\section{Đặc điểm phân bố ấu trùng, cá con ở cửa sông}

Đến nay, đã nghiên cứu đặc điểm phân bố của 20 loài ở khu vực cửa sồng Ka Long và cửa sông Tiên Yên cũng như chỉ rõ vai trò môi trường cửa sông đối với các loài cá, trong đó chủ yếu là do yếu tố độ mặn chi phối. Các loài đã xác định được đặc điểm phân bố ở cửa sông: Plecoglossus altivelis (Tran et al., 2012, 2014, 2017a, 2018a), Lateolabrax sp. (Trần Đức Hậu \& Tạ Thị Thủy, 2014; Tran et al., 2017c), Sillago sihama (Trần Đức Hậu và nnk., 2015a), Gobiopterus chuno (Trần Đức Hậu và nnk., 2015b), Terapon jarbua (Trần Trung Thành và nnk., 2015), Oryzias curvinotus (Tran \& Ta, 2016), Nuchequula nuchalis (Tran et al., 2016a), Hypoatherina valenciennei (Tran et al., 2016b), Opsariichthys (Tạ Thị Thủy \& Trần Trung
Thành, 2016), Branchigobius (Phùng Hữu Thỉnh và nnk., 2016), Takifugu niphobles (Trần Đức Hậu và nnk., 2017a), 5 loài thuộc bộ cá Pleuronectiformes (Pseudorhombus arsius, Tephrinectes sinensis, Brachirus orientalis, Solea ovata, Cynoglossus sp.) (Nguyễn Hà My và nnk., 2017), Ambassis vachellii (Tạ Thị Thủy và nnk., 2017), Redigobius bikolanus (Tran et al., 2018c) và 2 loài thuộc giống Gerres (Gerres japonicus và G. limbatus) (Tran et al., 2018b).

Từ tính đa dạng ấu trùng, cá con ở 3 khu vực cửa sông trên, có thể thây sự phân bố của nhiều loài chưa được hiểu rõ khi mỗi loài có xu hướng phân bố khác nhau, ví dụ: loài Oryzias curvinotus (Tran \& Ta, 2016) và loài Nuchequula nuchalis (Tran et al., 2016a) phân bố rộng và tập trung khu vực giữa cửa sông; trong khi loài Sillago sihama (Trần Đức Hậu và nnk., 2015a) chủ yếu phân bố ở khu vực ngoài cửa sông. Đối với các loài cá di cư (ví dụ Plecoglossus altivelis và Redigobius bikolanus) thì cửa sông có vai trò quan trọng đối với giai đoạn chuyển tiếp trong quá trình phát triển cá thể (Tran et al., 2018a; Tran et al., 2018c). Các kết quả này góp phần khẳng định môi trường cửa sông có liên quan đến bảo tồn các loài cá này. Hơn nữa, đặc điểm phân bố các loài cá khác nhau giữa các khu vực và được quyết định bởi đặc điểm cửa sông, điều kiện nước ở đó. Do vậy, tiềm năng lớn để phát hiện nhiều bí ẩn về giai đoạn sớm của cá ở các cửa sông khác.

\section{Hình thái ấu trùng, cá con ở cửa sông}

Mô tả đặc điểm hình thái là hướng nghiên cứu có nhiều ý nghĩa cơ bản trong nghiên cứu giai đoạn sớm của cá vì công tác định loại ấu trùng gặp nhiều khó khăn khi chúng có hình thái khác với giai đoạn trưởng thành. Dựa trên mẫu vật thu thập từ các cửa sông bắc Việt Nam, đến nay đã có 19 loài đã được vẽ hình, mô tả đặc điểm hình thái và sự phát triển cá thể: Plecoglossus altivelis (Tran et al., 2012), Lateolabrax sp. (Tran, 2013; Tran et al., 2017c), Sillago sihama (Trần Đức Hậu và nnk., 2014), Gerres limbatus (Tran et al., 2014b), Nuchequula nuchalis (Trần Trung Thành và nnk., 2014), Terapon jarbua (Trần Trung Thành và nnk., 2015), Oryzias 
curvinotus (Tran \& Ta, 2016), Hypoatherina valenciennei (Tran et al., 2016b), Takifugu niphobles (Hà Mạnh Linh và nnk., 2017), 5 loài thuộc bộ cá Pleuronectiformes (Pseudorhombus arsius, Tephrinectes sinensis, Brachirus orientalis, Solea ovata, Cynoglossus sp.) (Chu Hoàng Nam và nnk., 2017), 3 loài thuộc bộ cá Clupeiformes (Stolephorus commersonnii, Sardinella fimbriata và Konosirus punctatus) (Trần Đức Hậu \& Phạm Thị Thảo, 2017), Acanthopagrus latus (Nguyen et al., 2017) và Redigobius bikolanus (Tran et al., 2018c). Hình thái ấu trùng, cá con thu được ở Việt Nam đều được so sánh với các mô tả khác và thấy rằng chúng có những biến dị nhất định, kể cả giữa các địa điểm khác nhau ở Việt Nam.

\section{Hình thái đá tai của ấu trùng, cá con ở cửa sông}

Đã có những mô tả hình thái đá tai của 6 loài ở khu vực cửa sông Ka Long và sông Tiên Yên, gồm: Nuchequula nuchalis (Ta et al., 2015), Sillago sihama (Trần Đức Hậu và nnk., 2015), Hypoatherina valenciennei (Tran et al., 2016b), Terapon jarbua (Trần Đức Hậu và nnk., 2017b), Acanthopagrus latus (Hoang et al., 2017) và Ambassis vachellii (Trần Thị Kim Thoa và nnk., 2018). Thái đá tai có sự khác biệt giữa các loài, vì vậy đây là dấu hiệu tin cậy để định loại ấu trùng, cá con, đặc biệt đối với các loài khó định loại dựa vào hình thái ngoài. Mặc dù vậy, các kết quả nghiên cứu về đa dạng hình thái đá tai, sự bất đối xứng hình thái đá tai ở loài Acanthopagrus latus và loài Sillago sihama cho thấy có sự biến dị nhất định về hình thái, kích thước đá tai ở giai đoạn sớm giữa các khu vực khác nhau (Hoang et al., 2017; Ta et al., 2017). Ứng dụng đá tai trong xác định tuổi của từng cá thể, từ đó xác định được thời gian sinh sản, tốc độ sinh trưởng của loài cá Thơm thu được ở sông Ka Long và một số khu vực khác nhau của Nhật Bản (Tran et al., 2014). Đa dạng hình thái đá tai giai đoạn sớm của cá chưa được quan tâm nhiều ngay cả trên thế giới, vì vậy lĩnh vực này có nhiều tiềm năng để công bố những số liệu có ở Việt Nam.

\section{Một vài định hướng nghiên cứu giai đoạn sớm cá ở Việt Nam}

1. Hiện nay, một số nhà khoa học đã và đang từng bước tập hợp nhóm nghiên cứu giai đoạn sớm của cá ở các trường và viện: Trường Đại học Sư phạm Hà Nội, Trường Đại học Thủ Đô Hà Nội, Trường Đại học Khoa học Tự nhiên, ĐHQG Hà Nội, Viện Nghiên cứu Hải sản, Viện Hải Dương học Nha Trang và Viện Tài nguyên Môi trường Biển thuộc Viện Hàn lâm Khoa học Việt Nam. Tuy nhiên, cần tăng cường hơn nữa và thiết lập mới các hợp tác trong, ngoài nước, từng bước xây dựng nhóm nghiên cứu mạnh để thúc đẩy hướng nghiên cứu này ở Việt Nam.

2. Việt Nam với hệ thống sông ngòi dày đặc, nhiều cửa sông lớn có các đặc điểm thủy văn khác nhau. Điều đó tạo nên sự đa dạng hệ sinh thái và đa dạng sinh học. Do vậy, cần thiết tiến hành các nghiên cứu đa dạng thành phần loài, phân bố ấu trùng cá con ở các cửa sông khác ở Việt Nam để có bức tranh tổng thể cũng như dẫn liệu so sánh ở các vĩ độ khác nhau. Kết quả là cơ sở dữ liệu quan trọng trong khai thác, phát triển và bảo vệ nguồn lợi trong điều kiện các hệ sinh thái cửa sông đang bị nhiều tác động tiêu cực.

3. Tiếp tục mô tả giai đoạn sớm các loài cá thu được ở cửa sông và vùng nước xa bờ nhằm phục vụ cho việc xây dựng tài liệu hướng dẫn định loại ấu trùng, cá con ở Việt Nam. Có thể kết hợp với kỹ thuật phân tích di truyền phân tử để nghiên cứu về phân loại học một số loài khó định loại bằng hình thái. Cần tranh thủ sự đầu tư các quỹ, đề tài, sự hỗ trợ của các tổ chức, cơ quan đề có thể đầu tư các phương tiện chuyên ngành để thực hiện nội dung nghiên cứu này hiệu quả và chính xác.

4. Tập trung nghiên cứu đặc điểm phân bố, di cư các loài cá có giá trị ở khu vực cửa sông, góp phần cung cấp dữ liệu cho định hướng nuôi trồng, khai thác và bảo tồn. Các kết quả của nghiên cứu sinh học, sinh thái giai đoạn sớm của cá đều có ý nghĩa khoa học và thực tiễn cao. Sự đa dạng các kiểu thủy vực cùng với sự đa dạng các loài cá sẽ cho nhiều kết quả ý nghĩa khi thực hiện hướng nghiên cứu này. 
5. Tiếp tục nghiên cứu hình thái đá tai của ấu trùng, cá con và ứng dụng đá tai trong nghiên cứu mùa sinh sản, đặc điểm sinh trưởng và các vấn đề sinh thái khác của một số loài cá di cư, sử dụng khu vực cửa sông như vùng ương dưỡng. Không chỉ ở Việt Nam mà cả trên thế giới hướng nghiên cứu này dường như còn nhiều bỏ ngỏ vì những khó khăn khi thực hiện và thiếu trang thiết bị hiện đại. Tuy nhiên, các dẫn liệu thu được sẽ có ý nghĩa trong việc đánh giá các đặc điểm sinh học, sinh thái học giai đoạn sớm của cá; đó là những đặc điểm liên quan đến sự tồn tại, thích nghi và phát triển của chúng.

\section{KẾT LUẬN}

Trên đây là bức tranh khái quát về những nghiên cứu giai đoạn sớm của cá ở Việt Nam. Các công trình tập trung ở hai khu vực, đó là vùng nước xa bờ được tiến hành nghiên cứu gần đây với nhiều kết quả mang tính chất chung về đánh giá nguồn lợi, mùa vụ sinh sản hướng đến khai thác bền vững và vùng cửa sông ở Bắc Việt Nam. Các công trình cũng cung cấp những dẫn liệu về đa dạng thành phần loài, đặc điểm hình thái và đánh giá vai trò của khu vực đối với giai đoạn sớm cá từ ấu trùng đến cá con. Trên cơ sở này, bài báo đưa ra một vài định hướng nghiên cứu về lĩnh vực này ở Việt Nam.

Lời cảm ơn: Nghiên cứu này được tài trợ bởi Đề tài Nagao (Nhật Bản); Quỹ IFS (Thụy Điển), mã số A/5532-1; Quỹ Phát triển khoa học và Công nghệ (NAFOSTED) trong đề tài mã số: 106-NN.05-2014.03. Chúng tôi cảm ơn sự giúp đỡ từ các thành viên nhóm nghiên cứu Cá, Bộ môn Động vật học, Trường Đại học Sư phạm Hà Nội.

\section{TÀI LIỆU THAM KHẢO}

Delsman H. C., 1972. Fish eggs and larvae from the Java Sea (reprint of Delsman's 1921-1938 papers in Treubia). Linnaeus Press, Amsterdam.

Trần Văn Cường, Tử Hoàng Nhân, Phạm Quốc Huy, 2016. Đặc điểm nguồn giống cá, tôm ở vùng biển ven bờ và một số khu bảo vệ nguồn lợi tiềm năng. Tạp chí Nông nghiệp và Phát triển Nông thôn, 11: 48-58.
Fahay M. P., 2007. Early stages of fishes in the western north Atlantic Ocean (Davis Strait, Southern Greenland and Flemish Cap to Cape Hatteras). Northwest Atlantic Fisheries Organization, Dartmouth, NS.

Trần Đức Hậu, Nguyễn Thị Thịnh, Tạ Thị Thủy, 2014. Mô tả hình thái ấu trùng và cá con loài cá Đục bạc Sillago sihama (Forsskål, 1775) thu được ở cửa sông Tiên Yên. Tạp chí Khoa học Đại học Quốc gia Hà Nội, Khoa học Tụ nhiên và Công nghẹ, 30 (1S): 58-64.

Trần Đức Hậu, Tạ Thị Thủy, 2014. Phân bố ấu trùng và cá con loài cá vược Lateolabrax sp. ở sông Tiên Yên và Ka Long, Việt Nam. Tạp chí Khoa họ Đại họ Quốc gia Hà Nội, Khoa học Tự nhiên và Công nghệ, 30(6S): 137-142.

Trần Đức Hậu, Nguyễn Hà My, Nguyễn Thị Thịnh, 2015a. Phân bố ấu trùng và cá con loài cá Đục bạc (Sillago sihama) ở cửa sông Tiên Yên, Quảng Ninh, Việt Nam. Tạp chí Nông nghiệp và Phát triển Nông thôn, 17: 105-109.

Trần Đức Hậu, Trần Trung Thành, Nguyễn Hà My, Tạ Thị Thủy, 2015b. Phân bố cá bống chu nơ (Gobiopterus chuno) ở cửa sông Tiên Yên, Quảng Ninh. Tạp chí Khoa học Đại học Quốc gia Hà Nội, Khoa học Tụ nhiên và Công nghệ, 31(4S): 102-107.

Trần Đức Hậu, Nguyễn Thị Thịnh, Nguyễn Thị Thùy Dung, 2015c. Biến đổi hình dạng đá tai theo sự phát triển của ấu trùng và cá con loài cá Đục bạc (Sillago sihama Forsskal, 1775) ở cửa sông Tiên Yên, Quảng Ninh. Hội nghị khoa học toàn quốc về Sinh thái và Tài nguyên sinh vật lần thứ 6, Nxb Nông nghiệp: 1378-1383.

Trần Đức Hậu, Hà Mạnh Linh, Tạ Thị Thủy, Nguyễn Hà Linh, Phùng Hữu Thỉnh, 2017a. Đặc điểm phân bố ấu trùng và cá con của loài Takifugu niphobles (Jordan \& Snyder, 1901) ở cửa sông Tiên Yên và sông Ka Long, Bắc Việt Nam. Tạp chí Khoa hoc, Truòng Đại học Su phạm Hà Nội, 62(3): 97-106. 
Trần Đức Hậu, Nguyễn Phúc Hưng, Hà Mạnh Linh, 2017b. Nghiên cứu hình thái đá tai của ấu trùng và cá con loài cá Căng (Terapon jarbua) ở cửa sông Ka Long, Việt Nam. Hội nghị khoa học toàn quốc về Sinh thái và Tài nguyên sinh vật lần thứ 7. Nxb Khoa học Tự nhiên và Công nghệ, tr. 687-693.

Trần Đức Hậu, Phạm Thị Thảo, 2017. Hình thái giai đoạn sớm 3 loài thuộc bộ cá Trích (Clupeiformes) ở cửa sông Ka Long và Tiên Yên, Việt Nam. Tạp chí Sinh học, 39(2): 155-164.

Hoang K. D., Nguyen P. H., Tran D. H., 2017. Variations of otolith morphology of larval and juvenile yellow sea bream Acanthopagrus latus (Houttuyn, 1782) collected from northern Vietnam. The Annual Meeting of Asian Society of Ichthyologists. Ho Chi Minh city.

Phạm Quốc Huy, Tử Hoàng Nhân, Đào Thị Liên, Vũ Thị Hậu, 2014a. Xác định khu vực phân bố tập trung của trứng cá, cá con ở vùng biển vịnh Bắc Bộ, Việt Nam. Tạp chí Nông nghiệp và Phát triển Nông thôn, 9: 71-78.

Phạm Quốc Huy, Đào Thị Liên, Vũ Thị Hậu, Nguyễn Viết Nghĩa, 2014b. Hiện trạng thành phần loài và mật độ trứng cá, cá con ở vùng biển Việt Nam. Tạp chí Trương Đại hoc Cần Tho, 31: 106-115.

Phạm Quốc Huy, Nguyễn Khắc Bát, Đào Thị Liên, Vũ Thị Hậu, 2015. Biến động thành phần loài và mật độ trứng cá, cá con ở vùng đánh cá chung vịnh Bắc Bộ, giai đoạn 2011-2013. Tap chí Khoa hoc Đại học Quốc gia Hà Nội, Khoa học Tư nhiên và Công nghệ, 31(4S): 158-166.

Phạm Quốc Huy, Đào Thị Liên, Vũ Thị Hậu, 2017. Biến động thành phần loài và mật độ trứng cá, cá con họ cá Mối (Synodontidae) ở vùng biển vịnh Bắc Bộ, Việt Nam. Tạp chí Khoa họ và Công nghệ Biển, 17(2): 198-205.

Jeyaseelan M. J. P., 1998. Manual of fish eggs and larvae from Asian mangrove waters. UNESCO, Paris.
Kendall A. W., 2011. Identification of eggs and larvae of marine fishes. Tokai University Press, Hadano.

Leis J. M., Carson-Ewart B. M., 2000. The larvae of Indo-Pacific coastal fishes: a guide to identification, first edition. Brill, Leiden.

Leis J. M., Carson-Ewart B. M., 2004. The larvae of Indo-Pacific coastal fishes: a guide to identification, second edition. Brill, Leiden.

Leis J. M., Rennis D. S., 1983. The larvae of Indo-Pacific coral reef fishes. New South Wales University Press and University Press of Hawaii, Sydney and Honolulu.

Leis J. M., Trnski T., 1989. The larvae of Indo-Pacific shorefishes. New South Wales University Press and University Press of Hawaii, Sydney and Honolulu.

Hà Mạnh Linh, Tạ Thị Thuỷ, Phùng Hữu Thỉnh, Trần Đức Hậu, 2017. Mô tả hình thái ấu trùng và cá con loài cá nóc sao Takifugu niphobles (Jordan \& Snyder, 1901) ở khu vực cửa sông tỉnh Quảng Ninh. Tạp chí Khoa hoc, Truờng Đại học Su phạm Hà Nội 2, 49: 78-84.

McDowall R. M., 1988. Diadromy in fishes: migration between freshwater and marine environments. Croom Helm, London, UK.

Mito S., 1966. Fish eggs and larvae. Illustrated encyclopedia of the marine plankton of Japan, 7. Soyosha, Tokyo.

Moser H. G., 1996. The early stages of fishes in the California Current region. California Cooperative Oceanic Fisheries Investigations Atlas, 33: 1-1505.

Moser H. G., Richards W. J., Cohen D. M., Fahay M. P., Kendall A. W., Richardson S. L., 1984. Ontogeny and systematics of fishes, special publication No.1. American Society of Ichthyologists and Herpetologists, Lawrence, Kansas.

Nguyễn Hà My, Chu Hoàng Nam, Hoàng Thị Thảo, Trần Đức Hậu, 2017. Phân bố ấu trùng, cá con bộ cá Bơn (Pleuronectiformes) ở cửa sông $\mathrm{Ka}$ Long và Tiên Yên, tỉnh 
Quảng Ninh. Tạp chí Khoa họ Đại học Quốc gia Hà Nội, Khoa học Tụ nhiên và Công nghẹ, 33(2S): 26-31.

Nguyễn Hà My, Nguyễn Thị Thuỷ, Trần Đức Hậu, 2016. Mô tả hình thái ấu trùng và cá con loài Gerres erythrourus (Bloch, 1791) thu được ở cửa sông Ka Long, tỉnh Quảng Ninh. Hội nghị khoa học quốc gia lần thứ hai về Nghiên cứu và giảng dạy sinh học ở Việt Nam, Nxb Đại học Quốc gia Hà Nội, tr. 525-530.

Chu Hoàng Nam, Nguyễn Hà My, Nguyễn Xuân Huấn, Tạ Thị Thủy, Trần Đức Hậu, 2017. Hình thái ấu trùng, cá con bộ cá Bơn (Pleuronectiformes) ở ven bờ cửa sông Ka Long và Tiên Yên, tỉnh Quảng Ninh. Tạp chí Khoa hoc Đại học Quốc gia Hà Nội, Khoa hoc Tư nhiên và Công nghê, 33(2S): 32-37.

Neira F. J., Miskiewicz A. G., Trnski T., 1998. Larvae of temperate Australian fishes: laboratory guide for larval fish identification. University of Western Australia Press, Nedlands, Western Australia.

Nelson J. S., Grande T. C., Wilson M. V. H., 2016. Fishes of the world. Fifth edition. John Wiley \& Sons, Hoboken.

Đỗ Văn Nguyên, 1977. Thành phần, mật độ, và phân bố trứng cá - cá con ở vùng biển ven bờ từ Móng Cái-Quảng Ninh tới Cửa SótHà Tĩnh trong các năm 1975-1976. Báo cáo khoa học - Viện Nghiên cứu Hải Sản.

Đỗ Văn Nguyên, 1981. Báo cáo nghiên cứu trứng cá - cá con ở vùng biển từ Nghĩa Bình tới cửa Sót-Hà Tĩnh trong các năm 1975-1976. Viện Nghiên cứu Hải sản.

Đỗ Văn Nguyên, 1999. Báo cáo phân bố số lượng của trứng cá cá con ở vùng biển giữa Việt Nam và Thái Lan. Báo cáo khoa học - Viện Nghiên cứu Hải sản.

Đỗ Văn Nguyên, 2004. Thành phần loài và phân bô mật độ trứng cá - cá con ở vùng biển Đông và Tây Nam Bộ. Đề tài KC.CB.01.14 - Viện Nghiên cứu Hải sản.

Đỗ Văn Nguyên, Phạm Quốc Huy, 2007. Thành phần loài và phân bố mật độ trứng cá - cá con ở vùng đánh cá chung vịnh Bắc Bộ. Báo cáo khoa học - Viện Nghiên cứu Hải sản.

Đỗ Văn Nguyên, Phạm Quốc Huy, Nguyễn Viết Nghĩa, 2006. Hiện trạng thành phần loài và phân bố mật độ trứng cá cá con ở biển Việt Nam. Báo cáo chuyên đề - Viện Nghiên cứu Hải sản.

Nguyen H. P., Vo V. Q., Tran T. H. H., 2002. The fish eggs and larvae in coastal wates of Khanh Hoa province. Collection of Marine Research Works, XII: 205-214.

Okiyama M., 1988. An atlas of the early stage fishes in Japan. Tokai University Press, Tokyo.

Okiyama M., 2014. An atlas of early stage fishes in Japan second edition. Tokai University Press, Hadano.

Nguyễn Hữu Phụng, 1971. Bước đầu nghiên cứu trứng cá và cá bột ở vịnh Bắc Bộ. Nội san Nghiên cứu biển, 4: 32-39.

Nguyễn Hữu Phụng, 1973. Mùa vụ và phân bố của trứng cá và cá bột ven bờ tây vịnh Bắc Bộ. Tập san Sinh vật Địa học, 9(3-4): 115-120.

Nguyễn Hữu Phụng, 1976. Cá bột của loài cá Lưỡi búa Mene maculata (B. and S.) ở vịnh Bắc Bộ. Tập san Sinh vật Địa học, 14(3): 85-89.

Nguyễn Hữu Phụng, 1978. Trứng cá Cơm ở ven biển Quảng Ninh-Hải Phòng. Tuyển tập nghiên cứu biển, I(1): 175-189.

Nguyễn Hữu Phụng, 1980. Phân loại cá bột họ cá Mối Synodontidae ở vịnh Bắc Bộ. Tuyển tập nghiên cứu biển, II(1): 281-308.

Nguyễn Hữu Phụng, 1991. Trứng cá và cá bột vùng biển Việt Nam. Tuyển tập nghiên cứu biển, Tập III: 5-20.

Nguyễn Hữu Phụng, Hoàng Phi, Bùi Thế Phiệt, 1982. Điều tra sơ bộ trứng cá và cá bột ở vùng cửa sông Cửu Long. Tạp chí Sinh vật học, 4(2): 6-11.

Võ Văn Quang, Nguyễn Hữu Phụng, Trần Thị Hồng Hoa, 2004a. Trứng cá - cá bột qua mặt cắt Nha Trang (Việt Nam)-Luzon 
(Philippines) năm 2000. Tuyển tập Nghiên cứu Biền, XIV: 111-118.

Võ Văn Quang, Nguyễn Hữu Phụng, Trần Thị Hồng Hoa, 2004b. Trứng cá và cá bột vùng ven biển Bắc Bình Thuận. Hội nghị Khoa học Quốc gia "Biển Đồng - 2002", Viện Hải dương học, tr. 261-272.

Võ Văn Quang, Trần Thị Lê Vân, Nguyễn Hữu Phụng, 2010. Atlas sinh vật phù du trong vùng rạn san hô: Trứng cá- cá bột trong vùng rạn Cù Lao Chàm, Cù Lao Câu và Côn Đảo. Trong: Sinh vật phù du vùng rạn san hô Việt Nam: Cù Lao Chàm, Cù Lao Câu và Côn Đảo". Đoàn Như Hải, Nguyễn Ngọc Lâm (biên tập). Nxb Khoa học Tự nhiên \& Công nghệ, tr. 234-257.

Võ Văn Quang, Trần Thị Lê Vân, Nguyễn Thị Thanh Thủy, 2012. Thành phần, mật độ và sự phân bố trứng cá và cá bột vùng Đầm Thị Nại, tỉnh Bình Định. Tạp chí Khoa học và Công nghệ Biển, 12(1): 77-86.

Võ Văn Quang, 2013a. Nguồn giống cá và cá bột vùng đất ngập nước ven biển tỉnh Quảng Nam. Hội nghị khoa học toàn quốc về Sinh thái và Tài nguyên sinh vật lần thứ 5. Nxb Nông Nghiệp, tr. 1191-1197.

Võ Văn Quang, 2013b. Đặc điểm hình thái và sinh trưởng của cá bột loài cá cơm sọc xanh (Encrasicholina punctifer Fowler 1938). Tap chí Sinh hoc, 35(1): 23-31.

Võ Văn Quang, Lê Thị Thu Thảo, Trần Thị Hồng Hoa, Trần Công Thịnh, 2015. Biến động trứng cá và cá bột liên quan rạn san hô trong vịnh Nha Trang và lân cận. Tuyển Tập Nghiên Cứu Biển, 21(2): 106-117.

Nguyen H. X. A., Tran D. H., Tran T. T., 2017. Morphological variations of larvae and juveniles of Acanthopagrus latus collected from northern Vietnam. Proceedings of the 7th National Conference on Ecology and Biological Resources. Natural Science and Techonology Publishing House, tr. 548-553.

Richards W. J., 2006. Early stages of Atlantic fishes: an identification guide for the western central north Atlantic. Taylor \& Francis, Boca Raton, Florida.
Ta T. T., To T. D., Tran D. H., 2017. Asymmetry otoliths of Sillago sihama (Forsskal, 1775) in some areas of Vietnam. The Annual Meeting of Asian Society of Ichthyologists. Ho Chi Minh city.

Ta T. T., Tran D. H., Kinoshita I., Sashida M., Azuma K., 2011. Larval and juvenile ichthyofauna of the estuaries of the northern Vietnam. ISJ Meeting 44th, Hirosaki, Japan.

Ta T. T., 2014. Larval and juvenile fish assemblages of the Tien Yen Estuary, northern Vietnam. NEF Research Grant Programme. Final report. 38 pp.

Ta T. T., Tran D. H., Nguyen T. T. D., Tran T. T., 2015. Diversity of otolith morphology in Nuchequula nuchalis (Temminck \& Schlegel, 1845) larvae and juveniles collected in the Tien Yen estuary, northern Vietnam. Trop. Nat. Hist., 15(1): 69-79.

Trần Trung Thành, Trần Đức Hậu, Tạ Thị Thủy, 2014. Mô tả hình thái ấu trùng và cá con loài Nuchequula nuchalis (Temminck \& Schlegel, 1845). Tap chí Khoa hoc, Truờng Đại học Su phạm Hà Nội, 54: 117-124.

Trần Trung Thành, Trần Đức Hậu, Tạ Thị Thủy, 2015. Ấu trùng, cá con loài cá căng ong (Terapon jarbua) ở một số cửa sông miền Bắc Việt Nam. Hội nghị khoa học toàn quốc về Sinh thái và Tài nguyên sinh vật lần thứ $6, \mathrm{Nxb}$ Nông nghiệp, 315-320.

Trần Trung Thành, Hà Thị Ngọc, Trần Đức Hậu, 2017. Sự xuất hiện ấu trùng, cá con ở vùng nước ven bờ tại cửa sông Sò, tỉnh Nam Định. Tạp chí Sinh hoc, 39(2): 152-160.

Phùng Hữu Thỉnh, Trần Trung Thành, Chu Hoàng Nam, Trần Đức Hậu, 2016. Phân bố của ấu trùng, cá con của một loài cá bống điếu thuộc giống Branchigobius ở cửa sông Tiên Yên, Miền Bắc Việt Nam. Hội nghị toàn quốc lần thứ hai hệ thống bảo tàng thiên nhiên Việt Nam, Nxb Khoa học Tự nhiên và Công nghệ, tr. 640-645. 
Trần Thị Kim Thoa, Tô Thùy Dung, Trần Đức Hậu, 2018. Hình thái đá tai ấu trùng, cá con của cá sơn Ambassis vachellii (Richardson, 1846) ở cửa sông Ka Long, tỉnh Quảng Ninh. Hội nghị khoa học quốc gia lần thứ ba về Nghiên cứu và giảng dạy sinh học ở Việt Nam. Nxb Khoa học Tự nhiên và Công nghệ, tr. 298-304.

Tạ Thị Thủy, Trần Trung Thành, 2016. Giới hạn phân bố của ấu trùng, cá con Opsariichthys (Cypriniformes: Cyprinidae) ở cửa sông Tiên Yên, tỉnh Quảng Ninh. Tạp chí Khoa học, Trưòng Đại học Thủ đô Hà Nội, 2: 139-145.

Tạ Thị Thủy, Hà Mạnh Linh, Nguyễn Hà Linh, Trần Đức Hậu, 2017. Vai trò cửa sông Ka Long, tỉnh Quảng Ninh đối với ấu trùng và cá con loài Ambassis vachellii Richardson, 1846. Tạp chí Khoa học, Truòng Đại học Thủ đô Hà Nội, 18: 127-135.

Tran D. H., Kinoshita I., Ta T. T., Azuma K., 2012. Occurrence of the Ayu (Plecoglossus altivelis) larvae in northern Vietnam. Ichthyol. Res., 59: 169-178.

Tran D. H., 2013. Morphological description of juvenile of Lateolabrax sp. from the Tien Yen and Ka Long estuaries, Vietnam. Journal of Science, Ha Noi National University of Education, 58 (8): 3-8.

Tran D. H., Kinoshita I., Azuma K., Iseki T., Yagi Y., Nunobe J., Ta T.T., 2014. The potential biodiversity of Ayu, as evidenced by differences in its early development and growth between Vietnam and Japan. Environ. Biol. Fish., 97(12): 1387-1396.

Tran D. H., Ta T. T., 2016. Dependence of Hainan medaka, Oryzias curvinotus (Nichols \& Pope, 1927), on salinity in the Tien Yen estuary of northern Vietnam. Anim. Biol., 66: 49-64.

Tran D. H., Ta T. T., Tran T. T., 2016a. Importance of Tien Yen estuary (northern Vietnam) for early- stage Nuchequula nuchalis (Temminck \& Schlegel, 1845). Chiang Mai Univ. J. Nat. Sci., 15(1): 67-75.
Tran D. H., Tran T. T., Ta T. T., 2016b. Occurrence of Hypoatherina valenciennei (Bleeker, 1854) post-larvae and juveniles collected at estuarine habitats of northern Vietnam. Trop. Nat. Hist., 16(2): 107-117.

Tran D. H., Iida M. and Maeda K., 2017a. Downstream migration of newly-hatched ayu (Plecoglossus altivelis) in the Tien Yen River of northern Vietnam. Environ. Biol. Fish., 100: 1329-1341.

Tran D. H., Ta T. T., Kinoshita I., Tran T. T., 2017b. Larval and juvenile ichthyofauna in estuaries of the northern Vietnam. The annual meeting of Asian Society of Ichthyologists. Hochiminh City.

Tran D. H., Kinoshita I., Nguyen X. H., Miller T. W., Ta T. T., Tran T. T., 2018a. Early life stages and habitats of the Ayu (Plecoglossus altivelis) based on data from the southernmost populations in two river-estuary systems in Vietnam. Asian Fish. Sci., 31: 1-16.

Tran T. T., Tran D. H., Chu H. N., Ta T. T., 2018b. Habitat segregation of Gerres japonicus and G. limbatus in early stages in the Tien Yen estuary, northern Vietnam. Academia Journal of Biology, 40(4): 133-141.

Tran T. T., Tran D. H., Kinoshita I., 2017c. Occurrence of two types of larvae of the Asian seaperch (Lateolabrax) in the northern estuaries of Vietnam. Ichthyol. Res., 64(2): 244-249.

Tran T. T., Tran D. H., Nguyen X. H., 2018c. Larval description and habitat utilization of an amphidromous goby, Redigobius bikolanus (Gobiidae). Anim. Biol., 68: 15-26.

Tran T. T., Tran D. H., Ta T. T., 2014. Morphological description of Saddleback silver-biddy (Gerres limbatus) larvae and juveniles from the Tien yen estuary, Vietnam. Journal of Science, Hanoi National University of Education, 59(9): 3-9. 
Tran D. H., 2017. Importance of the Ka Long Estuary located in northern Vietnam as a nursery ground for fishes. IFS Fund, code A/5532-1. Final report. 21 pp.

Uchida K., Imai S., Mito S., Fujita S., Ueno M., Shojima Y., Senta T., Tahuku M., Dotu Y., 1958. Studies on the eggs, larvae and juvenile of Japanese fishes-Series I.
Sec. Lab. Fish. Biol., Fish. Dep. Fac. Agr. Kyushu. Univ., Fukuoka.

Yagi Y., Kinoshita I., Fujita S., Ueda H., Aoyoma D., 2009. Comparison of the early life histories of two Cynoglossus species in the inner estuary of Ariake Bay, Japan. Ichthyol. Res., 56: 363-371. 